\title{
Effects of Loblolly Pine Extract, Primary and Quaternary Alkyl Ammonium Chlorides Combined with Burgundy Oil from Eastern Red Cedar against Subterranean Termites and Wood-Decay Fungi
}

\author{
Fred J. Eller, ${ }^{\mathrm{a}, *}$ Mark E. Mankowski, ${ }^{\mathrm{b}}$ Grant T. Kirker, ${ }^{\mathrm{c}}$ and Gordon W. Selling ${ }^{\mathrm{d}}$ \\ Burgundy oil (BO) from Eastern red cedar provides resistance against \\ termites and wood-decay fungi and is enhanced when combined with an \\ amylose inclusion complex (AIC) containing hexadecylammonium chloride \\ (HAC). Indirect evidence also indicated that a methanol Loblolly pine extract \\ (LPE) was inhibitory against termites. This study compared the effects of \\ HAC and didecyldimethylammonium chloride (DDAC) combined with LPE \\ and $\mathrm{BO}$ on termites and wood-decay fungi. Southern pine was treated by \\ vacuum/pressure impregnation and resistance evaluated after exposure to \\ termites and decay fungi. The combination of $\mathrm{BO}$ and either $\mathrm{HAC} / \mathrm{AIC}$ or \\ DDAC/AIC reduced wood mass losses by termites, increased termite \\ mortality, and inhibited all wood-decay fungi. The HAC/AIC and DDAC/AIC \\ resulted in equivalent mass losses by termites and termite mortalities. The \\ DDAC was slightly more inhibitory than the HAC against wood-decay fungi. \\ Given the slight advantage of DDAC over HAC and because DDAC is \\ currently used to preserve wood, DDAC might be preferred over HAC. The \\ LPE had a very minor effect on mass loss by termites, termite mortality, and \\ only a slight inhibitory effect on $G$. trabeum and $T$. versicolor, while $R$. \\ placenta and I. lacteus were unaffected. Higher concentrations of DDAC \\ and/or LPE might improve protection against termites and wood-decay fungi.
}

Keywords: Juniperus virginiana; Wood extract; Southern pine; Reticulitermes flavipes; Brown-rot fungi; White-rot fungi

Contact information: a: United States Department of Agriculture, Agricultural Research Service, National Center for Agricultural Utilization Research, Functional Foods Research Unit, 1815 North University Street, Peoria, IL 61604, USA; b: United States Department of Agriculture, Forest Service, Forest Products Laboratory, Durability and Wood Protection, 201 Lincoln Green, Starkville, MS 39759, USA; c: United States Department of Agriculture, Forest Service, Forest Products Laboratory, Durability and Wood Protection, One Gifford Pinchot Drive, Madison, WI 53726-2398, USA; d: United States Department of Agriculture, Agricultural Research Service, National Center for Agricultural Utilization Research, Plant Polymer Research Unit, 1815 North University Street, Peoria, IL 61604, USA;

* Corresponding author: Fred.Eller@USDA.gov

Mention of trade names or commercial products in this article is solely for the purpose of providing scientific information and does not imply recommendation or endorsement by the U.S. Department of Agriculture. USDA is an equal opportunity provider and employer.

\section{INTRODUCTION}

Continually evolving wood protection methods emphasize the use of chemicals that minimize concerns with toxicity and harm to the environment, and there has been considerable effort to employ natural products with little or no mammalian toxicity (Singh and Singh 2012). Derivatives from a wide range of plant parts for wood protection have 
been reviewed including phenolics, tannins, essential oils, resins, and lignans (Yang 2009; Singh and Singh 2012). The wood-decay antifungal activities of wood extractives, such as terpenes and metal scavengers, are reviewed by Valette et al. (2017).

The treatment of a non-durable wood with an extract from a durable wood species (i.e., transferrable durability) is a promising technique (Kirker et al. 2013; 2016: Hassan et al. 2017). This method is particularly efficient if the extracts originate from a sustainable waste or by-product (Saha Tchinda et al. 2018). Extractives from heartwood of several tree species have been shown to be particularly effective. Representative species include black locust, Chinese coffin tree, Western red cedar, Alaska cypress, white cypress-pine, and Chinese incense-cedar (Smith et al. 1989; Chang et al. 1999, 2000; Taylor et al. 2002; Watanabe et al. 2005; Taylor et al. 2006; Yen et al. 2008; Wu et al. 2012). Heartwood extractives and durability has been reviewed by Taylor et al. (2002).

Numerous reports discuss the use of essential oils or extracts for wood preservation. There are many reports of antifungal activity (Morita et al. 1997; Chang et al. 1999, 2000; Cheng et al. 2005; Wang et al. 2005a,b; Wu et al. 2005; Cheng et al. 2006; Kazemi et al. 2006; Cheng et al. 2008; Yen et al. 2008; Cheng et al. 2011, 2012; Wu et al. 2012; Li et al. 2013; Tascioglu et al. 2013; Mansour and Salem 2015; Salem et al. 2016; Xie et al. 2017). Some report anti-termitic activity (French et al. 1979; Zhu et al. 2001; Chang and Cheng 2002; Watanabe et al. 2005; Taylor et al. 2006; Gupta et al. 2011) and a few report both antifungal and anti-termitic activity (Cheng et al. 2004; Pandey et al. 2012; Xie et al. 2015).

The plant family Cupressaceae, in particular, has several examples of active essential oils or extracts with anti-termitic activity (French et al. 1979; Chang et al. 2001), antifungal activity (Morita et al. 1997; Cheng et al. 2005; Wu et al. 2005; Wan et al. 2007; Wang et al. 2011), or both (Chang et al. 2003; Taylor et al. 2006). In addition, sesquiterpenes from Cupressaceae have been identified to have both anti-termitic (Watanabe et al. 2005; Mankowski et al. 2016; Hassan et al. 2017) and antifungal activities (Bauch et al. 2004; Cheng et al. 2005).

Eastern red cedar (ERC) (Juniperus virginiana L.) (Cupressaceae) is an abundant natural resource in the United States and represents an underutilized renewable natural product with several potential uses (Eller 2018). Eastern red cedar heartwood is resistant to subterranean termites (Carter and Smythe 1974; Arango et al. 2006; Kard et al. 2007; Kose and Taylor 2012; Konemann et al. 2014), and extracts of ERC sawdust have shown promise as a wood preservative by their termiticidal activity (Adams et al. 1988; Carter 1976; McDaniel et al. 1989; Eller et al. 2010, 2018, 2020) or reduction in termite attack (McDaniel and Dunn 1994; Eller et al. 2010, 2018, 2020). In addition, ERC extracts have shown antifungal activity against brown-rot and white rot decay fungi (Eller et al. 2010; Tumen et al. 2013; Eller et al. 2018, 2020). Using a different extraction method, Kirker et al. (2016) found only a marginal durability improvement for the ERC extract against wood decay fungi. The resistance of ERC heartwood to fungal decay is illustrated by Smith and Glaeser (2013) in an interesting photograph showing a skeletonized ERC tree with heartwood remaining after attack.

The authors' laboratory has investigated the use of cedarwood oil (CWO) (CAS 8000-27-9), as a wood preservative against termites and wood-decay fungi (Eller et al. 2010; Tumen et al. 2013; Eller et al. 2018, 2020). Cedarwood oil is an essential oil mixture of sesquiterpenes with a high percentage of cedrol (CAS 77-53-2) (Adams 1991).

Non-polar solvents including hexane, supercritical, and liquid $\mathrm{CO}_{2}$ have been used to extract CWO from ERC heartwood (Eller 2018). If a non-polar solvent is used first to 
remove the CWO from ERC sawdust, a burgundy solid (BS) can subsequently be removed separately using a polar solvent like methanol (Tumen et al. 2013). A burgundy-colored oil (BO), which is a mixture of CWO and BS, can be extracted from ERC heartwood sawdust if a polar solvent such as methanol is used first (Tumen et al. 2013). All three of these extracts (i.e., CWO, BO, and BS) have been tested for their biological activity against subterranean termites, brown-rot decay fungi, and white-rot decay fungi (Eller et al. 2010; Tumen et al. 2013; Eller et al. 2018, 2020). In general, these studies showed that CWO significantly reduced wood mass loss by termites and increased termite mortality. The BS has only very minor activity against termites, and the BO is equal to the CWO in bioactivity. For the decay fungi studied, CWO inhibited both the brown-rot and white-rot decay fungi. The BS inhibited the white-rot more than the brown-rot decay fungi. Accordingly, the $\mathrm{BO}$ was more active than $\mathrm{CWO}$ against the white-rot decay fungi. Cedrol, a major component of CWO and a sesquiterpene alcohol, has previously been reported to have anti-termitic activity (McDaniel et al. 1989) and antifungal activity (Chang et al. 1999; Cheng et al. 2011; Mun and Prewitt 2011; Wang et al. 2011). The sesquiterpenes in CWO have also been reported to be responsible for the antifungal activity of CWO and BO against brown-rot fungi (Bauch et al. 2004; Mun and Prewitt 2011).

An amylose inclusion complex (AIC) was used as an aqueous emulsifier for CWO to pressure treat wood (Eller et al. 2018) because the AIC confers both emulsification properties and water resistance (Hay et al. 2019; Fanta et al. 2016). By chance, the AIC used contained hexadecylammonium chloride (HAC) (CAS 1602-97-7), and the HAC/AIC by itself significantly reduced wood mass loss by termites and was highly termiticidal but had only relatively minor effects on the wood-decay fungi (Eller et al. (2018). Subsequently, Eller et al. (2020) found the BO in combination with the HAC/AIC resulted in the highest termite mortality and the best overall protection against termites and decay fungi. Only after the study was completed, were the chemical similarities between HAC and didecyldimethylammonium chloride (DDAC) (CAS 7173-51-5), a compound already used to pressure treat wood, realized. Although DDAC is currently used to treat wood, the relative bioactivities of HAC and DDAC are unknown. Both HAC and DDAC are ammonium chlorides (AC), but HAC is a primary alkyl amine and DDAC is a quaternary alkyl amine in addition to their differences in their alkyl chain lengths.

Loblolly pine blocks exposed to polar solvents including ethanol or methanol sustained more termite mass loss and lower termite mortality than blocks exposed only to water (Eller et al. 2018, 2020). This suggests that exposure of the test wood blocks to these polar solvents removes extractables from the pine blocks that are inhibitory to the termites and increases termite mortality. It was hypothesized that treating wood blocks with an extract of pine would result in both lower mass loss by termites and higher termite mortality.

The objective of this study was to investigate the relative effectiveness of AICs prepared with HAC or DDAC in combination with a loblolly pine extract (LPE) and burgundy oil (BO) extracted from ERC on subterranean termites and four species of wood decay fungi (two brown-rot and two white-rot). Wood blocks were treated by vacuum/pressure impregnation and subsequently exposed to termites and wood decay fungi. Treatment effectiveness was evaluated by measuring wood mass loss and termite mortality. 


\section{EXPERIMENTAL}

\section{Burgundy Oil}

The burgundy oil (BO) solution used to treat the wood test samples consisted of a 1:1 mixture of CWO and burgundy solid (BS) dissolved in methanol (MeOH). The CWO was extracted using supercritical $\mathrm{CO}_{2}\left(70{ }^{\circ} \mathrm{C}, 27.6 \mathrm{MPa}\right)$ from ERC heartwood sawdust as previously described (Eller and King 2000), and the BS was extracted as described by Eller et al. (2020). Briefly, ERC heartwood sawdust was first extracted with refluxing n-hexane in a Soxhlet extractor to remove CWO. After allowing residual hexane to evaporate from the hexane-extracted sawdust, the sawdust was subsequently extracted with refluxing methanol $(\mathrm{MeOH})$ in a Soxhlet extractor to yield the BS.

\section{Soxhlet Extraction of Loblolly Pine}

In order to investigate polar constituents in the loblolly pine, a Soxhlet extraction was performed on $100 \mathrm{~g}$ of loblolly pine sawdust with refluxing methanol (EMD Millipore Corp., Billerica, MA) for 10 cycles. The methanol was separated from the solution by rotary evaporation (Buchi Rotavapor RE 120 with a vertical condenser, New Castle, DE), and the loblolly pine extract (LPE) mass was determined and the dry-mass yield was calculated after drying the extracted sawdust overnight in a vacuum oven $\left(105{ }^{\circ} \mathrm{C}\right.$ and $-0.088 \mathrm{MPa})$. There were three replications of Soxhlet extractions.

\section{Amylose Inclusion Complex (AIC)}

The AICs were composed of 95\% high-amylose corn starch and 5\% alkyl ammonium chloride (AC). The primary alkyl AC, hexadecylammonium chloride (HAC) (CAS 1602-97-7), was prepared as detailed previously (Eller et al. 2018), and the quaternary AC, didecyldimethylammonium chloride (DDAC) (CAS 7173-51-5) was purchased (Santa Cruz Biotechnology, Dallas, TX, USA). Deionized water (1800 mL) and $100 \mathrm{~g}$ of high-amylose corn starch ( $68 \%$ amylose, AmyloGel 03003, Cargill, Minneapolis, MN, USA) were mixed in a Waring blender (Torrington, CT, USA) and passed through a steam jet-cooker. To this hot starch dispersion, a solution of $5.25 \mathrm{~g} \mathrm{AC}$ in $200 \mathrm{~g}$ of hot $\left(90^{\circ} \mathrm{C}\right)$ water was added and mixed for $1 \mathrm{~min}$ at high speed. The resulting alkyl AC/AIC colloidal suspensions were cooled and freeze dried. The impregnation treatment solutions contained 2\% alkyl AC/AIC (HAC/AIC or DDAC/AIC) and 2\% polyvinyl alcohol (PVOH) (MW 133,000, 99 mol\% hydrolyzed, Polysciences, Warrington, PA, USA).

\section{Treatment Descriptions}

The seven wood block treatments tested were: Water Only Control $\left(\mathrm{H}_{2} \mathrm{O}\right)$; Water after Methanol $\left(\mathrm{MeOH}>\mathrm{H}_{2} \mathrm{O}\right)$; Water after LPE in Methanol $\left(\mathrm{LPE} / \mathrm{MeOH}>\mathrm{H}_{2} \mathrm{O}\right)$; DDAC/Amylose Inclusion Complex after BO in Methanol (BO/MeOH>DDAC/AIC); HAC/Amylose Inclusion Complex after $\mathrm{BO}$ in Methanol (BO/MeOH $>\mathrm{HAC} / \mathrm{AIC}$ ); DDAC/Amylose Inclusion Complex after $\mathrm{BO}+\mathrm{LPE}$ in Methanol (BO+LPE/MeOH> DDAC/AIC); and HAC/Amylose Inclusion Complex after BO+LPE in Methanol (BO+LPE/MeOH $>\mathrm{HAC} / \mathrm{AIC}$ ).

The $\mathrm{BO} / \mathrm{MeOH}$ solution contained $5.0 \% \mathrm{CWO}$ and $5.0 \% \mathrm{BS}$ by weight. The $\mathrm{LPE} / \mathrm{MeOH}$ solution contained $3.4 \% \mathrm{LPE}$ by weight. The BO+LPE/MeOH treatment contained $5.0 \%$ CWO, 5.0\% BS and 3.4\% LPE by weight. 


\section{Vacuum/Pressure Impregnation}

Vacuum/pressure impregnation was used to treat the wood test blocks as described by Eller et al. (2018). Southern pine blocks $(2.54 \mathrm{~cm} \times 2.54 \mathrm{~cm} \times 0.64 \mathrm{~cm})$ were used for termite tests, and $1-\mathrm{cm}^{3}$ southern pine and $1-\mathrm{cm}^{3}$ yellow poplar blocks were used for the brown-rot and white-rot fungal tests, respectively. Wood was purchased locally and milled to size in the laboratory. Briefly, after conditioning $\left(25^{\circ} \mathrm{C}\right.$ and $50 \% \mathrm{RH}$ for termite blocks and $25{ }^{\circ} \mathrm{C}$ and $70 \% \mathrm{RH}$ for fungal blocks) to a constant mass, blocks were submerged under a given treatment solution and held under vacuum $(-0.088 \mathrm{MPa})$ for $30 \mathrm{~min}$ and then pressurized to $0.69 \mathrm{MPa}$ for $60 \mathrm{~min}$. Blocks were weighed immediately after impregnation. For treatments with two impregnations (i.e., $\mathrm{MeOH}>\mathrm{H}_{2} \mathrm{O} ; \quad \mathrm{LPE} / \mathrm{MeOH}>\mathrm{H}_{2} \mathrm{O}$; $\mathrm{BO} / \mathrm{MeOH}>\mathrm{DDAC} / \mathrm{AIC} ; \mathrm{BO} / \mathrm{MeOH}>\mathrm{HAC} / \mathrm{AIC} ; \mathrm{BO}+\mathrm{LPE} / \mathrm{MeOH}>\mathrm{DDAC} / \mathrm{AIC}$; and $\mathrm{BO}+\mathrm{LPE} / \mathrm{MeOH}>\mathrm{HAC} / \mathrm{AIC}$ ), the blocks were re-conditioned as described above to a constant mass after the first impregnation treatment. The blocks were then impregnated with the second treatment, immediately weighed, and re-conditioned to a constant mass a second time. This allowed the determination of the incorporation rates of the components of the first and second impregnations. All blocks were weighed prior to exposure to termites or wood-decay fungi.

\section{Termite Resistance}

Reticulitermes flavipes (Kollar) (Blattodea: Rhinotermitidae) were collected from a single colony found in a dead $\log$ at Sam D. Hamilton Noxubee National Wildlife Refuge (Starkville, Mississippi). Cut log sections containing the termites were kept in 30-gallon trashcans and maintained in the laboratory at $25^{\circ} \mathrm{C}$ in darkness. The day of the test setup, termites were removed from the collected log sections by breaking the rotting wood open and shaking the termites out of the wood through a screen to catch large debris. Termites were placed in plastic tubs with moistened paper towels for $2 \mathrm{~h}$ before being counted with an aspirator.

A no-choice bioassay based on studies described by Kard and Mallette (1997), Konemann et al. (2014), Eller et al. (2018), and Lipeh et al. (2020) was used to evaluate resistance of the treated wood test samples. Resistance was evaluated based on wood mass loss and termite mortality. These tests used smaller numbers of termites (100 to 150 workers), containers, and substrate compared to methods like AWPA E1-17. As termites can be sometimes difficult to collect in large numbers and counting large numbers can be laborious, the authors prefer to use these types of test parameters. Cylindrical plastic containers (Pioneer Plastics 002C, $50.8 \mathrm{~mm} \mathrm{D} \mathrm{x} 36.5 \mathrm{~mm} \mathrm{H}$ ) were filled with $50 \mathrm{~g}$ of washed, dried, screened, sterilized sand. The sand used was American Countryside All Purpose Sand purchased from Lowes. The sand was washed and rinsed three times using deionized water, oven dried at $100{ }^{\circ} \mathrm{C}$ overnight, then sifted using a 600 micron screen \#30. Sifted sand was autoclaved at $121^{\circ} \mathrm{C}$ and 15 psi for 45 minutes, allowed to cool overnight, and autoclaved a second time and allowed to cool. To the sand, $9 \mathrm{~mL}$ of sterile deionized water was added to create a moisture content of $18 \%$. The containers with sand and water were allowed to sit for one hour, and a small plastic grid (25mm x $25 \mathrm{~mm}$ Gutter Guard) was added on top of the wet sand. The test wood samples used in the test measured 2.54 $\mathrm{cm} \times 2.54 \mathrm{~cm} \times 0.64 \mathrm{~cm}$. This is the sample size suggested in the AWPA E1-17 (AWPA 2020) and other studies (Kard and Mallette 1997; Konemann et al. 2014). Wood samples were placed on the plastic grid so they were not in contact with the damp sand approximately 2 to $3 \mathrm{~mm}$ above sand surface. One-hundred fifty worker termites were added to each container (Kard and Mallette 1997). Worker termites were only used, as 
very few soldier termites were found in the collected termite colony. Containers were kept in darkness at room temperature and relative humidity $\left(21^{\circ} \mathrm{C}, 55 \% \mathrm{RH}\right)$ for 28 days. At the end of the test, living termites were counted, test sample blocks were cleaned and conditioned to a constant mass at $25{ }^{\circ} \mathrm{C}$ and $50 \%$ relative humidity (RH). Wood mass loss and termite mortality were then calculated. The seven treatments were replicated six times.

\section{Wood-Decay Fungi Resistance}

Soil bottle assays were conducted according to AWPA E10-16 (2012) to compare the efficacy of actives. Two brown-rot fungi, Gloeophyllum trabeum (Pers.) Murrill (1908) (MAD-617) and Rhodonia (Postia) placenta (Fr.) Niemelä, K.H.Larss. \& Schigel (2005) (MAD-698), and two white-rot fungi, Trametes versicolor (L.) Lloyd (1920) (MAD-697) and Irpex lacteus (Fr.) Fr. (1828) (HHB-7328), were used in experiments with treated southern pine and yellow poplar, respectively. Cultures were grown and maintained on malt extract agar (MEA) plates prior to experiments. Two 5-mm plugs from the actively growing edge of petri dish cultures of brown-rot fungi were added to sterile soil bottles containing $40 \times 30 \times 3 \mathrm{~mm}$ southern pine feeder strips, while maple feeders were used for the white-rot fungi. Fungi were allowed to grow and colonize the feeders for three weeks at $27{ }^{\circ} \mathrm{C}$ and $70 \%$ humidity prior to adding $1-\mathrm{cm}^{3}$ southern pine or yellow poplar test blocks. Test blocks were propylene gas sterilized overnight in vials separated by treatment, and then one or two blocks were added to each bottle in a sterile hood. Bottles were placed in the controlled humidity incubator for eight weeks, and then blocks were removed and scraped clean of fungal mycelium. Test blocks were oven dried at $60{ }^{\circ} \mathrm{C}$ for $4 \mathrm{~h}$ to stop fungal growth, followed by one week of conditioning at $27{ }^{\circ} \mathrm{C}$ and $30 \%$ humidity, and conditioned weights were recorded. Percent weight loss from the initial weight of conditioned blocks was calculated and reported. The seven treatments were replicated six times for each fungal species.

\section{Statistical Analyses}

Statistix ${ }^{\mathrm{TM}} 8.1$ software (Analytical Software, Tallahassee, FL, USA) was used to perform statistical analyses of the data. Box and whisker plots were examined to identify and remove outliers. A Levene's homogeneity of variance test was performed to determine if values needed to be transformed in order to satisfy analyses of variance (ANOVA) assumptions. Single-factor ANOVA were performed on the percentage wood mass loss for the termites, percentage termite mortality, and percentage wood mass loss for each of the four fungal species tested after arcsine square-root transformation (i.e., $\arcsin * \sqrt{ }$ proportion mass loss) to stabilize the variance. Linear contrasts were performed to compare treatments with LPE against treatments without LPE as well as to compare treatments with DDAC against those with HAC. Statistical analyses were performed on transformed data but untransformed means are presented for ease of interpretation. Treatment means were compared using least significant difference (LSD) in case of a significant F-test $(\mathrm{P} \leq 0.05)$.

\section{RESULTS AND DISCUSSION}

\section{Soxhlet Extraction of Loblolly Pine}

The methanol Soxhlet extraction of the Loblolly pine yielded a semi-solid ambercolored material with a dry-mass yield of LPE of $3.35 \%$ and scent reminiscent of freshly cut pine wood. 


\section{Vacuum/Pressure Impregnation}

After re-conditioning to a constant mass, the mean percentage mass changes for the treated wood samples are shown in Table 1. The alkyl AC/AIC solutions used to treat the wood samples contained $2 \% \mathrm{PVOH}$ and $2 \%$ alkyl AC/AIC; therefore, half of the observed approximate $4.0 \%$ mass increase for the samples treated with alkyl AC/AIC is from the $\mathrm{PVOH}$ and half is from the alkyl AC/AIC. Because the alkyl AC/AIC itself contained 5\% alkyl AC, the observed $4.0 \%$ percentage mass gains for the wood samples treated with alkyl AC/AIC contained ca. $0.1 \%$ alkyl AC (i.e., $2 \%$ X 5\%=0.001 =0.1\%).

There was a small mass loss observed for $\mathrm{H}_{2} \mathrm{O}$ (i.e., - $-0.7 \%$ ). For the $\mathrm{MeOH}>\mathrm{H}_{2} \mathrm{O}$ treatment, there was a small mass loss after both $\mathrm{MeOH}$ (i.e., $-0.8 \%$ ) and $\mathrm{H}_{2} \mathrm{O}$ (i.e., $-0.4 \%$ ) exposures. The wood blocks treated with the LPE were slightly more yellow than the blocks exposed to either water only $\left(\mathrm{H}_{2} \mathrm{O}\right)$ or methanol and water $\left(\mathrm{MeOH}>\mathrm{H}_{2} \mathrm{O}\right)$ indicating the amber color of the LPE was conferred to the wood during impregnation. All of the wood blocks treated with any of the four treatments containing BO were burgundy colored after impregnation.

Table 1. Mean Percentage Wood Block Mass Changes after Impregnation Treatments

\begin{tabular}{|l|c|c|c|}
\hline & \multicolumn{3}{|c|}{ Mean Percentage Change ${ }^{\text {a }}$} \\
\hline Treatment & First Impregnation & & Second Impregnation \\
\hline $\mathrm{H}_{2} \mathrm{O}$ & -0.7 & & na \\
\hline $\mathrm{MeOH}>\mathrm{H}_{2} \mathrm{O}$ & -0.8 & $>$ & -0.4 \\
\hline $\mathrm{LPE} / \mathrm{MeOH}>\mathrm{H}_{2} \mathrm{O}$ & 1.8 & $>$ & -0.3 \\
\hline $\mathrm{BO} / \mathrm{MeOH}>\mathrm{DDAC} / \mathrm{AIC}$ & 7.3 & $>$ & 4.0 \\
\hline $\mathrm{BO} / \mathrm{MeOH}>\mathrm{HAC} / \mathrm{AIC}$ & 7.5 & $>$ & 4.0 \\
\hline $\mathrm{BO}+\mathrm{LPE} / \mathrm{MeOH}>\mathrm{DDAC} / \mathrm{AIC}$ & 10.4 & $>$ & 3.9 \\
\hline $\mathrm{BO}+\mathrm{LPE} / \mathrm{MeOH}>\mathrm{HAC} / \mathrm{AIC}$ & 10.2 & $>$ & 4.0 \\
\hline
\end{tabular}

a Percentage $(\mathrm{N}=30)$ changes based on initial pre-impregnation conditioned wood block masses. na stands for not applicable.

\section{Termite Resistance}

Box and whisker plots identified one probable outlier replication in the $\mathrm{H}_{2} \mathrm{O}$ treatment with both low percentage mass loss and $100 \%$ termite mortality, and this single outlier replication was removed from the data set prior to analysis. The percentage mass losses for the termites are shown in Fig. 1A. The ANOVA indicated the treatment effect for percentage mass loss was highly significant $\left(\mathrm{F}_{6,34}=606 ; \mathrm{P}=0.0000\right)$. The $\mathrm{H}_{2} \mathrm{O}$ only control and $\mathrm{MeOH}>\mathrm{H}_{2} \mathrm{O}$ treatments had the highest mass losses and were statistically equivalent to one another. The $\mathrm{LPE} / \mathrm{MeOH}>\mathrm{H}_{2} \mathrm{O}$ treatment had statistically lower mass loss than either the $\mathrm{H}_{2} \mathrm{O}$ or $\mathrm{MeOH}>\mathrm{H}_{2} \mathrm{O}$ treatments, although by only a relatively small amount (i.e., 7.7 versus 8.6 and $8.6 \%$, respectively). The linear contrast was significant ( $\mathrm{T}$ $=2.24 ; \mathrm{P}=0.032$ ) for a mass loss difference between treatments with or without LPE. In a study with a similar methodology, Kard and Mallette (1997) saw much higher mass loss on southern pine wood exposed to 100 worker termites. Due to contamination issues in our laboratory incubators, the present study was run at a slightly lower temperature $\left(21^{\circ} \mathrm{C}\right)$ than earlier studies $\left(23\right.$ to $24^{\circ} \mathrm{C}$ ). This may have led to a reduction in the amount of feeding in the control treatments. We believe in the validity of our test because, as will be discussed, termite mortality in the control treatments was very low indicating the termites were not having an issue feeding in the control treatments. We also used AWPA E1-17 sized blocks (large) for the number of termites tested. 


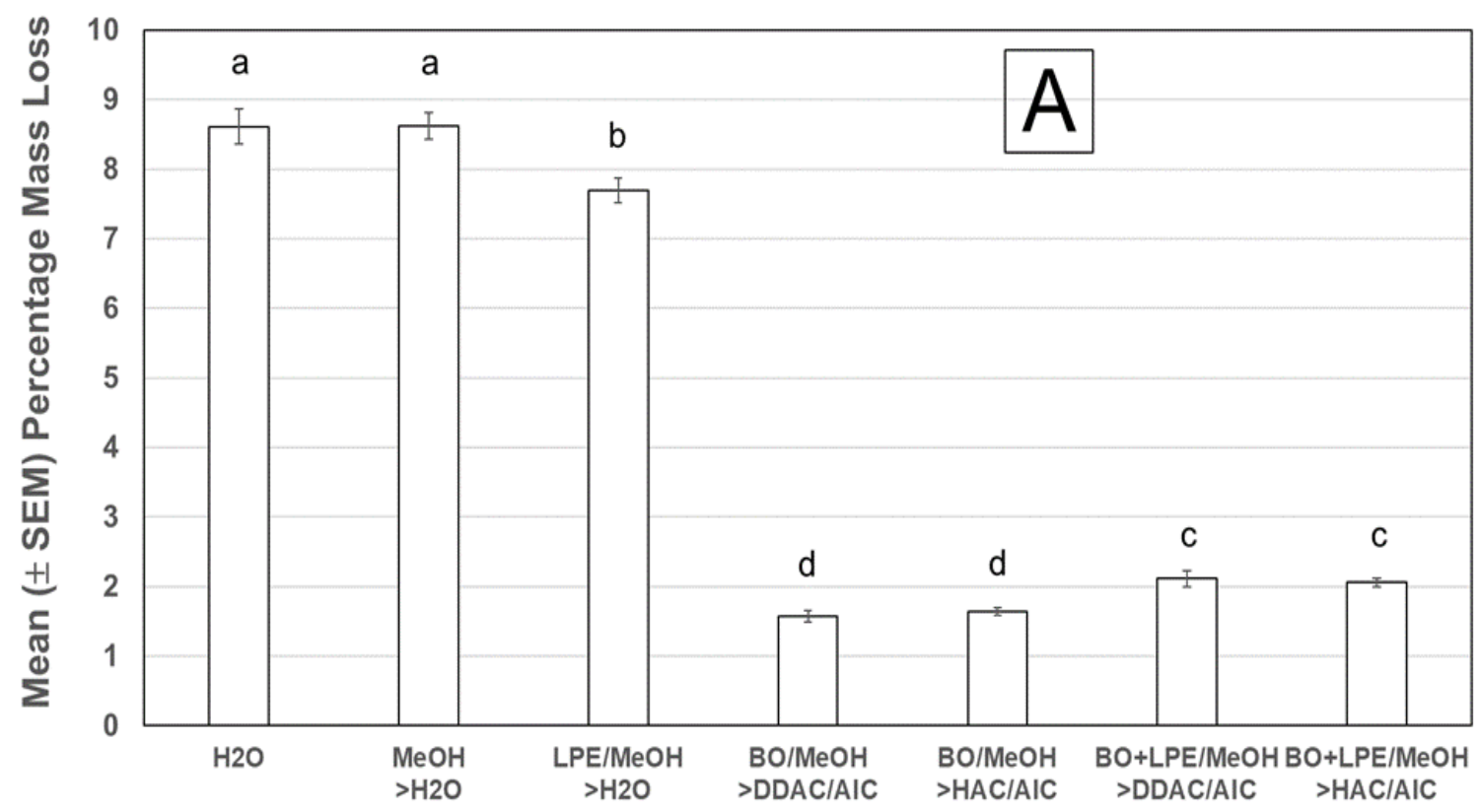

Treatment

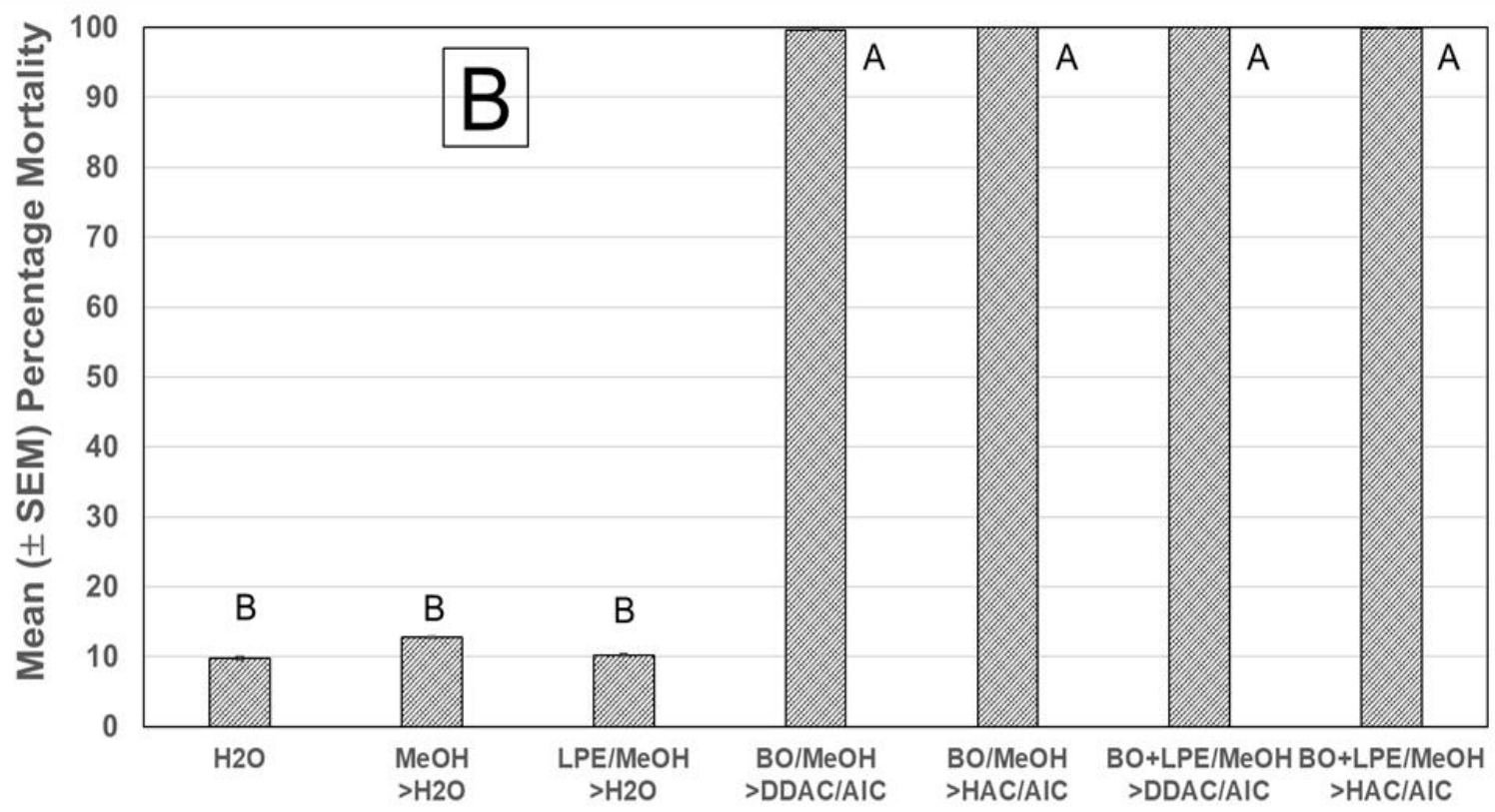

Treatment

Fig. 1. (A) Mean ( $\pm S E M)$ percentage wood mass losses for treated loblolly pine samples exposed to subterranean termites (open bars with lower case letters) and (B) mean ( \pm SEM) percentage subterranean termite mortality (shaded bars with upper case letters). Means without letters in common differ significantly using Least Significant Difference $(P \leq 0.05)$.

The percentage termite mortalities are shown in Fig. 1B. The ANOVA indicated that the treatment effect for percentage termite mortality was highly significant $\left(\mathrm{F}_{6,34}=\right.$ 457; $\mathrm{P}=0.0000$ ). The $\mathrm{H}_{2} \mathrm{O}, \mathrm{MeOH}>\mathrm{H}_{2} \mathrm{O}$ and $\mathrm{LPE} / \mathrm{MeOH}>\mathrm{H}_{2} \mathrm{O}$ treatments all had low termite mortalities and were statistically equivalent to one another. The linear contrast was 
not significant $(\mathrm{T}=0.37 ; \mathrm{P}=0.716$ ) for a termite mortality difference between treatments with or without LPE. The very low mortality (9.73\%) in the $\mathrm{H}_{2} \mathrm{O}$ only treatment was indicative of excellent termite vigor for this test.

The treatments which included $\mathrm{BO}$ and either the DDAC/AIC or HAC/AIC (i.e., $\mathrm{BO} / \mathrm{MeOH}>\mathrm{DDAC} / \mathrm{AIC}, \mathrm{BO} / \mathrm{MeOH}>\mathrm{HAC} / \mathrm{AIC}, \mathrm{BO}+\mathrm{LPE} / \mathrm{MeOH}>\mathrm{DDAC} / \mathrm{AIC}$, and $\mathrm{BO}+\mathrm{LPE} / \mathrm{MeOH}>\mathrm{HAC} / \mathrm{AIC}$ ) all had very high termite mortalities (i.e., ca. 100\%) and were statistically equivalent to one another. All four of these treatments were significantly higher than the $\mathrm{H}_{2} \mathrm{O}, \mathrm{MeOH}>\mathrm{H}_{2} \mathrm{O}$ and $\mathrm{LPE} / \mathrm{MeOH}>\mathrm{H}_{2} \mathrm{O}$ treatments. Treatments $\mathrm{BO} / \mathrm{MeOH}>\mathrm{DDAC} / \mathrm{AIC}$ and $\mathrm{BO} / \mathrm{MeOH}>\mathrm{HAC} / \mathrm{AIC}$ were statistically equivalent to one another as were $\mathrm{BO}+\mathrm{LPE} / \mathrm{MeOH}>\mathrm{DDAC} / \mathrm{AIC}$ and $\mathrm{BO}+\mathrm{LPE} / \mathrm{MeOH}>\mathrm{HAC} / \mathrm{AIC}$. The linear contrast was not significant $(\mathrm{T}=0.16 ; \mathrm{P}=0.870)$ for termite mortality difference between treatments with DDAC or HAC.

\section{Brown-Rot Decay Fungi Resistance}

There were two contaminated replications in the $R$. placenta data, one in the $\mathrm{H}_{2} \mathrm{O}$ treatment and one in the $\mathrm{BO} / \mathrm{MeOH}>\mathrm{DDAC} / \mathrm{AIC}$ treatment, and these two replications were omitted from the statistical analysis. The percentage mass losses for the brown-rot fungi are shown in Fig. 2. The ANOVAs indicated significant treatment effects for both $G$. trabeum and $R$. placenta $\left(\mathrm{F}_{6,35}=27.1 ; \mathrm{P}=0.0000\right.$ and $\mathrm{F}_{6,33}=28.4 ; \mathrm{P}=0.0000$, respectively).

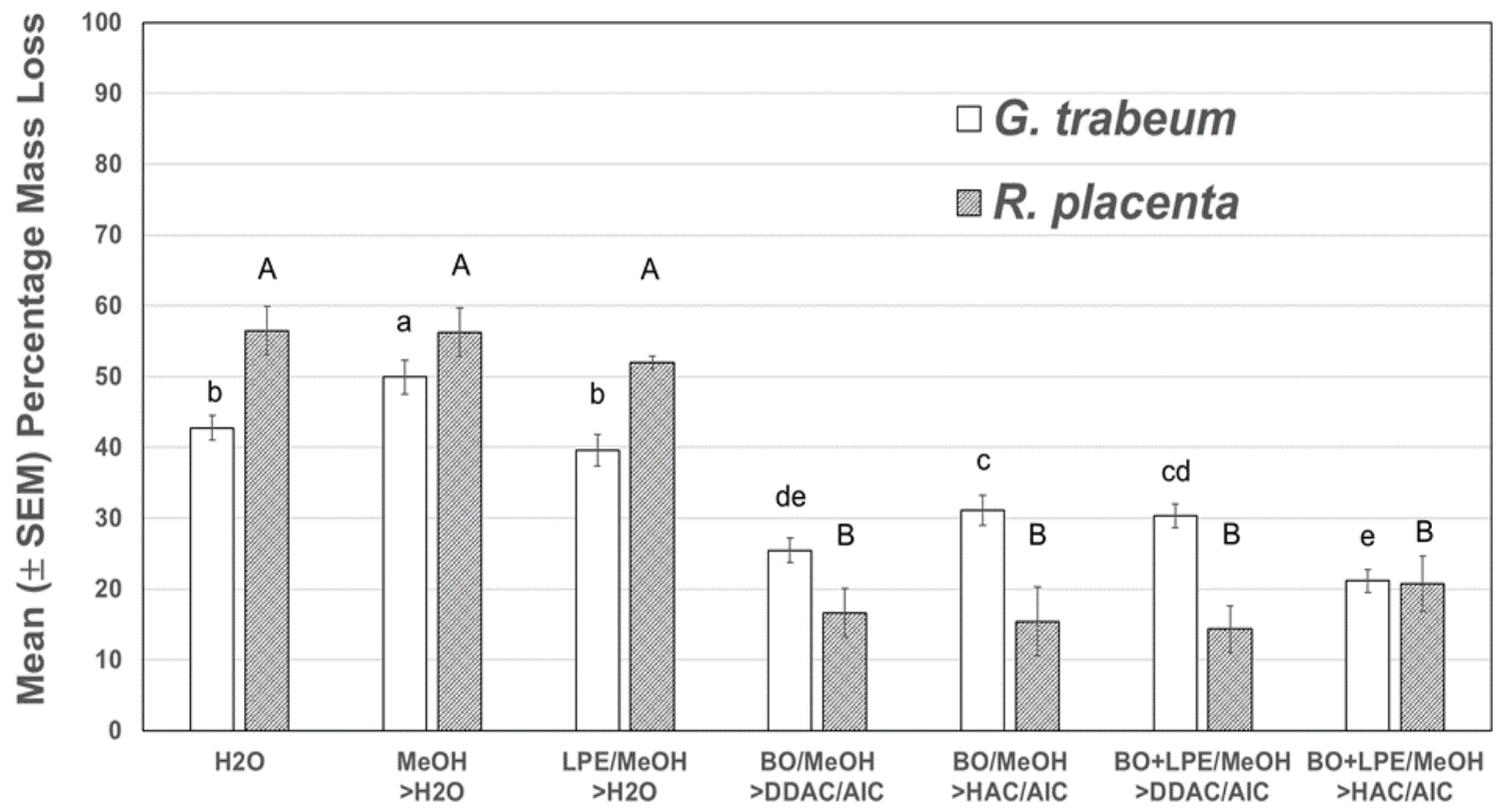

Treatment

Fig. 2. Mean $( \pm S E M)$ percentage mass losses for treated loblolly pine samples exposed to brown-rot decay fungi Gloeophyllum trabeum (open bars with lower case letters) and Rhodonia placenta (shaded bars with upper case letters). For a given fungal species, means without letters in common differ significantly using Least Significant Difference $(P \leq 0.05)$.

For G. trabeum, wood mass loss was highest for the $\mathrm{MeOH}>\mathrm{H}_{2} \mathrm{O}$ treatment. Mass loss was significantly higher than both the $\mathrm{H}_{2} \mathrm{O}$ and LPE/MeOH $>\mathrm{H}_{2} \mathrm{O}$ treatments. However, the $\mathrm{H}_{2} \mathrm{O}$ and $\mathrm{LPE} / \mathrm{MeOH}>\mathrm{H}_{2} \mathrm{O}$ treatments were statistically equivalent. For $G$. 
trabeum, the linear contrast was not significant $(\mathrm{T}=1.78 ; \mathrm{P}=0.083)$ for a mass loss difference between treatments with or without LPE. For $R$. placenta, on the other hand, the $\mathrm{H}_{2} \mathrm{O}, \mathrm{MeOH}>\mathrm{H}_{2} \mathrm{O}$ and $\mathrm{LPE} / \mathrm{MeOH}>\mathrm{H}_{2} \mathrm{O}$ treatments were statistically equivalent, and the contrast was not significant $(\mathrm{T}=0.01 ; \mathrm{P}=0.991)$ for a mass loss difference between treatments with or without LPE.

For both G. trabeum and R. placenta, treatments which included BO and either AC (i.e., $\mathrm{BO} / \mathrm{MeOH}>\mathrm{DDAC} / \mathrm{AIC}, \mathrm{BO} / \mathrm{MeOH}>\mathrm{HAC} / \mathrm{AIC}, \mathrm{BO}+\mathrm{LPE} / \mathrm{MeOH}>\mathrm{DDAC} / \mathrm{AIC}$, and $\mathrm{BO}+\mathrm{LPE} / \mathrm{MeOH}>\mathrm{HAC} / \mathrm{AIC}$ ) had significantly less mass loss than the $\mathrm{H}_{2} \mathrm{O}, \mathrm{MeOH}>\mathrm{H}_{2} \mathrm{O}$ and $\mathrm{LPE} / \mathrm{MeOH}>\mathrm{H}_{2} \mathrm{O}$ treatments. For the brown-rot decay fungi, neither AC was consistently more effective than the other. For $G$. trabeum, without LPE, the $\mathrm{BO} / \mathrm{MeOH}>\mathrm{DDAC} / \mathrm{AIC}$ had less mass loss than $\mathrm{BO} / \mathrm{MeOH}>\mathrm{HAC} / \mathrm{AIC}$. However, with $\mathrm{LPE}, \mathrm{BO}+\mathrm{LPE} / \mathrm{MeOH}>\mathrm{DDAC} / \mathrm{AIC}$ had more mass loss than $\mathrm{BO}+\mathrm{LPE} / \mathrm{MeOH}>$ HAC/AIC. For $R$. placenta, there were no significant differences between any of these four treatments. The linear contrasts were not significant for a mass loss difference between treatments with DDAC or treatments with HAC for either $G$. trabeum or $R$. placenta $(\mathrm{T}=1.06 ; \mathrm{P}=0.296$ and $\mathrm{T}=0.48 ; \mathrm{P}=0.631$, respectively $)$.

The inclusion of LPE in addition to the BO and either AC/AIC (i.e., DDAC/AIC or HAC/AIC) did not lead to a consistently lower mass loss. For G. trabeum, the inclusion of LPE led to a lower mass loss when HAC was used; however, the treatments $\mathrm{BO} / \mathrm{MeOH}>\mathrm{DDAC} / \mathrm{AIC}$ and $\mathrm{BO}+\mathrm{LPE} / \mathrm{MeOH}>\mathrm{DDAC} / \mathrm{AIC}$ were statistically equivalent.

\section{White-Rot Decay Fungi Resistance}

The percentage mass losses for the white-rot fungi are shown in Fig. 3. The ANOVAs indicated significant treatment effects for both $T$. versicolor and I. lacteus $\left(\mathrm{F}_{6,35}\right.$ $=31.5 ; \mathrm{P}=0.0000$ and $\mathrm{F}_{6,35}=3.14 ; \mathrm{P}=0.014$, respectively).

For T. versicolor, wood mass loss was highest for the $\mathrm{MeOH}>\mathrm{H}_{2} \mathrm{O}$ treatment and was significantly higher than the LPE/MeOH> $\mathrm{H}_{2} \mathrm{O}$ treatment, although the $\mathrm{H}_{2} \mathrm{O}$ and $\mathrm{LPE} / \mathrm{MeOH}>\mathrm{H}_{2} \mathrm{O}$ treatments were statistically equivalent. For $T$. versicolor, the overall linear contrast was not significant $(\mathrm{T}=1.19 ; \mathrm{P}=0.244)$ for a mass loss difference between treatments with or without LPE. For I. lacteus, the $\mathrm{H}_{2} \mathrm{O}, \mathrm{MeOH}>\mathrm{H}_{2} \mathrm{O}$ and $\mathrm{LPE} / \mathrm{MeOH}>\mathrm{H}_{2} \mathrm{O}$ treatments were statistically equivalent. The overall linear contrast was not significant $(\mathrm{T}=0.40 ; \mathrm{P}=0.694)$ for a mass loss difference between treatments with or without LPE for I. lacteus.

Although treatments that included $\mathrm{BO}$ and either $\mathrm{AC}$ (i.e., $\mathrm{BO} / \mathrm{MeOH}>\mathrm{DDAC} / \mathrm{AIC}$, $\mathrm{BO} / \mathrm{MeOH}>\mathrm{HAC} / \mathrm{AIC}, \mathrm{BO}+\mathrm{LPE} / \mathrm{MeOH}>\mathrm{DDAC} / \mathrm{AIC}$, and $\mathrm{BO}+\mathrm{LPE} / \mathrm{MeOH}>\mathrm{HAC} / \mathrm{AIC})$ had significantly less mass loss than the $\mathrm{H}_{2} \mathrm{O}, \mathrm{MeOH}>\mathrm{H}_{2} \mathrm{O}$ and $\mathrm{LPE} / \mathrm{MeOH}>\mathrm{H}_{2} \mathrm{O}$ treatments for $T$. versicolor, only the $\mathrm{BO}+\mathrm{LPE} / \mathrm{MeOH}>\mathrm{DDAC} / \mathrm{AIC}$ had an inhibitory effect against I. lacteus. For T. versicolor, the DDAC treatments had less mass loss than did the HAC treatments. For I. lacteus, the $\mathrm{BO}+\mathrm{LPE} / \mathrm{MeOH}>\mathrm{DDAC}$ treatment had significantly less mass loss than did the $\mathrm{BO}+\mathrm{LPE} / \mathrm{MeOH}>\mathrm{HAC} / \mathrm{AIC}$ treatment. The linear contrast was significant for a mass loss difference between treatments with DDAC or treatments with HAC for T. versicolor $(\mathrm{T}=5.69 ; \mathrm{P}=0.000)$; however, this contrast was not significant for I. lacteus $(\mathrm{T}=0.40 ; \mathrm{P}=0.694)$.

The inclusion of LPE in addition to the BO and either AC/AIC (i.e., DDAC/AIC or HAC/AIC) did not lead to a significant lower mass loss for either T. versicolor or I. lacteus. In fact, for $T$. versicolor, the mass loss for the $\mathrm{BO}+\mathrm{LPE} / \mathrm{MeOH}>\mathrm{HAC}$ treatment (i.e., $28.4 \%$ ) was significantly higher than the mass loss for the $\mathrm{BO} / \mathrm{MeOH}>\mathrm{HAC}$ treatment (i.e., $14.2 \%)$. 


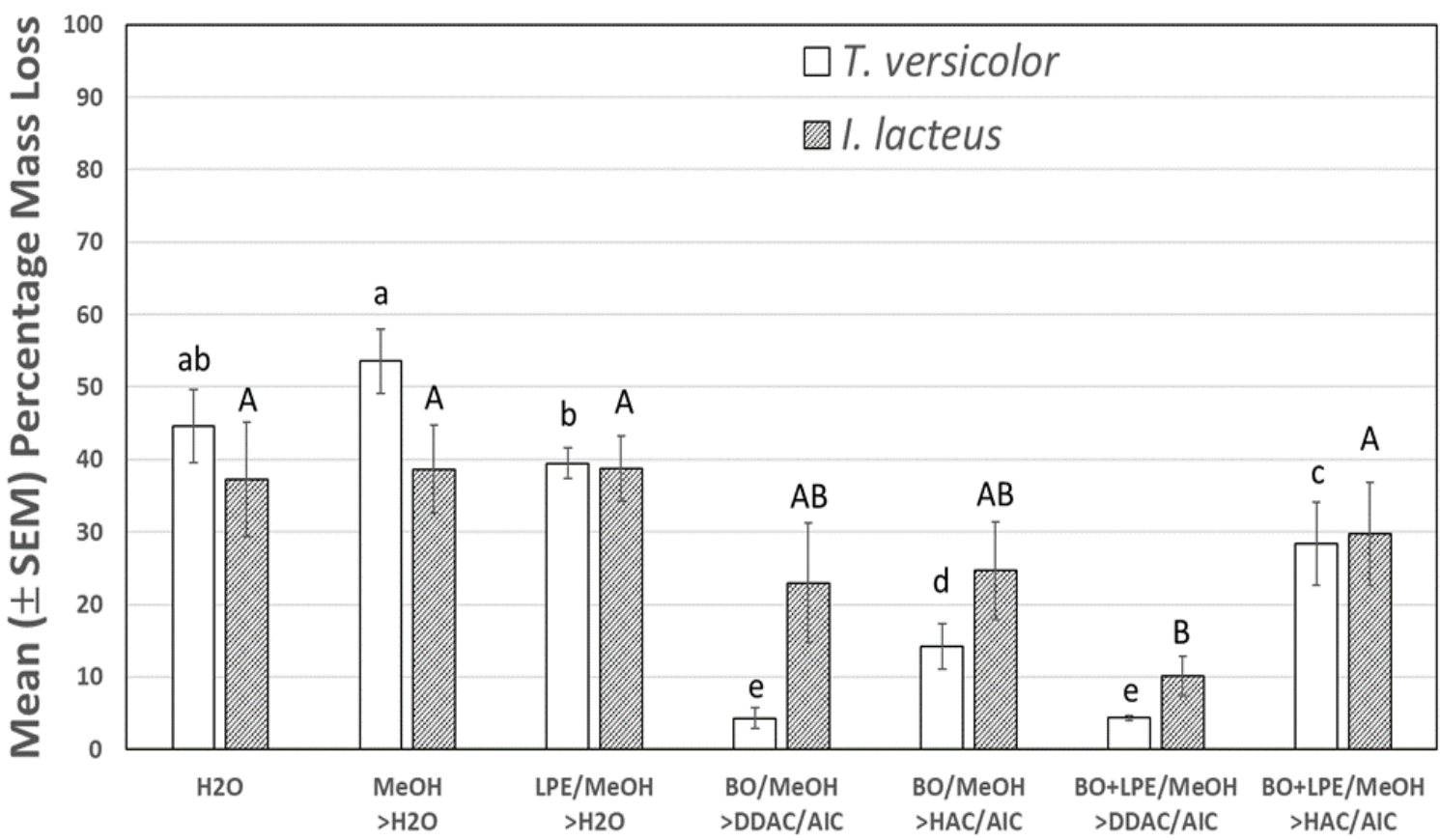

Treatment

Fig. 3. Mean ( \pm SEM) percentage mass losses for treated yellow poplar samples exposed to white-rot decay fungi Trametes versicolor (open bars with lower case letters) and Irpex lacteus (shaded bars with upper case letters). For a given fungal species, means without letters in common differ significantly using Least Significant Difference $(P \leq 0.05)$.

Although leaching studies have not been performed for these treatments, it is unlikely that these test compounds would be easily leached from the treated wood. Both $\mathrm{CWO}$ and $\mathrm{BS}$ are insoluble in water, and HAC/AIC has previously been demonstrated to inhibit both water absorption and wood swelling (Eller et al. 2018). In addition, the LPE is not water soluble either. Therefore, exposure of wood with these treatments to water will not cause them to be removed from the wood.

The four treatments that included BO and either the DDAC/AIC or HAC/AIC all had both very low termite percentage mass loss as well as very high termite mortality, and the two alkyl AC/AICs (i.e., DDAC/AIC and HAC/AIC) were effectively equivalent. The combination of an alkyl AC and $\mathrm{BO}$ gave excellent protection against termites. Similar results were reported for $\mathrm{BO}>\mathrm{HAC} / \mathrm{AIC}$ (Eller et al. 2020). As far as is known, Eller et al. (2020) and this report are the only studies testing an essential oil and an alkyl AC together against termites and wood decay fungi.

Previously, because the CWO>HAC/AIC and $\mathrm{BO}>\mathrm{HAC} / \mathrm{AIC}$ treatments were statistically equivalent, it was concluded that the $\mathrm{CWO}$ alone is largely responsible for both the lower mass loss and the higher termite mortality observed and that the effect of the BS on termites is relatively minor (Eller et al. 2020). Therefore, for protection against termites, CWO alone could be used instead of BO in conjunction with either DDAC/AIC or HAC/AIC.

The anti-fungal activities of the two alkyl ACs were very similar in their effectiveness. In only one case did the HAC have greater antifungal activity than DDAC; mass loss for $G$. trabeum on wood treated with BO+LPE/MeOH $>$ HAC/AIC was 
significantly less than mass loss on wood treated with $\mathrm{BO}+\mathrm{LPE} / \mathrm{MeOH}>\mathrm{DDAC} / \mathrm{AIC}$. Otherwise, the two ACs were either statistically equivalent or the DDAC was more inhibitory than the HAC.

Exposure of the wood blocks to $\mathrm{MeOH}$ caused a slight decrease in wood block mass and indicates that $\mathrm{MeOH}$ extracts something from the wood, which is consistent to previous reports (Eller et al. 2018, 2020). In addition, treating wood blocks with the LPE led to a slight decrease in percentage wood mass loss by termites, although the addition of the LPE did not increase termite mortality. These results are similar to earlier reports that polar solvents such as ethanol or methanol can extract inhibitory materials from the loblolly pine test wood blocks making them both more palatable and less toxic (Eller et al. 2018, 2020). However, even though the observed LPE effect on termite mass loss was statistically significant, it was very minor and probably of little practical use.

The wood-decay fungal data indicate that the $\mathrm{MeOH}$ removed something that was inhibitory against $G$. trabeum and $T$. versicolor and that the LPE could add back this inhibition for these two species. It is hypothesized that the $\mathrm{MeOH}$ extracts compounds such as terpenes, resins, and/or lignans, which might otherwise be inhibitory. However, $R$. placenta and I. lacteus were not affected by the LPE. Using a higher concentration of LPE might lead to a higher level of protection against termites and wood-decay fungi. It also possible that other materials not tested in combination with the BO and AC/AIC such as the metal chelator, EDTA (Schultz and Nicholas 2002), or a radical or oxidant scavenger (Singh and Singh 2012) could increase treatment effectiveness.

Both the LPE and BS required a polar solvent such as $\mathrm{MeOH}$ as the diluent/carrier to solubilize these compounds during impregnation. If the LPE and BS were not included in an impregnation treatment, the potential hazards of using a toxic and flammable solvent such as $\mathrm{MeOH}$ could be avoided. If used alone, $\mathrm{CWO}$ could be formulated in an aqueous emulsion (e.g., with HAC/AIC or DDAC/AIC) to pressure treat wood. The water-based carrier method would be non-flammable and less costly.

\section{CONCLUSIONS}

1. The combination of burgundy oil (BO) and either the didecyldimethylammonium chloride amylose inclusion complex (DDAC/AIC) or the hexadecylammonium chloride amylose inclusion complex (HAC/AIC) resulted in low percentage wood mass losses by termites (i.e., ca. $80 \%$ less than Control), nearly $100 \%$ termite mortality, and this combination represents a very effective treatment against termites. In addition, this combination inhibited all four wood decay fungi species studied. The antifungal effects were more varied for the wood-decay fungi studied, and the combination of BO and either AC/AIC resulted in between 20 and $90 \%$ less mass loss by wood-decay fungi, depending on the species.

2. The didecyldimethylammonium chloride amylose inclusion complex (DDAC/AIC) and hexadecylammonium chloride amylose inclusion complex (HAC/AIC) resulted in equivalent mass losses by termites as well as equivalent termite mortalities. Therefore, either could be used and similar protection against termites would be expected. For the wood-decay fungi, the DDAC was slightly more inhibitory than the HAC. Because of their similar activities, the choice of one alkyl AC over the other could be based on the relative costs of the two ACs. However, given the slight overall advantage of DDAC 
over HAC and the fact that DDAC is already used to preserve wood, DDAC might be preferred.

3. The concentration of AC used in this experiment was only $0.1 \%$, which is lower than what is commonly used to treat wood. AWPA Standard T1 (2020) and AWPA A1616 (2016) give minimum quaternary alkyl ammonium chloride retentions ranging from 0.18 to $0.86 \%$ for southern pine with a standard density of $500 \mathrm{~kg} / \mathrm{m}^{3}$. In addition, EU Directive 98/8/EC (2012) reports a final concentration of DDAC of between 0.3 and $1.8 \%$. These concentrations represent an approximate 2-fold to 18-fold higher concentration than the $0.1 \%$ we used in this study. A higher concentration of AC would undoubtedly lead to more effective inhibition of the wood-decay fungi.

4. The addition of the LPE did not lead to a large increase in protection of treated wood against termites. Also, at the concentration of LPE tested, only a slight inhibitory effect of LPE on G. trabeum and T. versicolor was observed. The other two species of wooddecay fungi (i.e., R. placenta and I. lacteus) were unaffected.

\section{ACKNOWLEDGEMENTS}

The authors wish to thank Jeffrey Teel for technical assistance. Thanks to Amy Bishell at the USDA-FS-FPL (Madison, WI) who performed the AWPA E10 soil bottle tests and Craig Bell and Shawn Cooper at USDA-FS-FPL (Starkville, MS), who helped with termite collection and tests. Deb Palmquist assisted with statistical analyses. This research was supported in part by the U.S. Department of Agriculture, Agricultural Research Service.

\section{REFERENCES CITED}

Adams, R. P. (1991). "Cedarwood oil: Analyses and properties," Mod. Meth. Plant Anal. 12, 159-173. DOI: 10.1007/978-3-642-84023-4_8

Adams, R. P., McDaniel, C. A., and Carter, F. L. (1988). "Termiticidal activities in the heartwood, bark/sapwood and leaves of Juniperus species from the United States," Biochem. Sys. Ecol. 16, 453-456. DOI: 10.1016/0305-1978(88)90043-9

ASTM D1105-96 (2014). "Standard test method for preparation of extractive-free wood," ASTM International, West Conshocken, PA, USA.

AWPA E10-12 (2016). "Standard method of testing wood preservatives by laboratory soil block cultures," American Wood Protection Association, Birmingham, AL, USA.

AWPA A16-16 (2016). "Standard method for determining didecyldimethyl ammonium compounds in treated wood by HPLC," American Wood Protection Association, Birmingham, AL, USA.

AWPA E1-17 (2020). "Laboratory method for evaluating the termite resistance of woodbased materials: Choice and no-choice tests," American Wood Protection Association, Birmingham, AL, USA.

AWPA Standard T1 (2020). "Table 3.2," American Wood Protection Association, Birmingham, AL, USA.

Arango, R. A., Green III, F., Hintz, K., Lebow, P. K., and Miller, R. B. (2006). "Natural durability of tropical and native woods against termite damage by Reticulitermes 
flavipes (Kollar)," Inter. Biodeterior. Biodegrad. 57, 146-150. DOI:

10.1016/j.ibiod.2006.01.007

Bauch, J., Puls, J., Klupsch, R., and Vogel, C. (2004). "Biological and chemical characteristics of "included sapwood" of Juniperus virginiana L.," Holzforschung 58, 74-81. DOI: $10.1515 /$ HF.2004.010

Carter, F. (1976). "Responses of subterranean termites to wood extractives," Mater. Organ. Beiheft. 3, 357-364.

Carter, F. L., and Smythe, R. V. (1974). "Feeding and survival responses of Reticulitermes flavipes (Kollar) to extractives of wood from 11 coniferous genera," Holzforschung 28, 41-45. DOI: 10.1515/hfsg.1974.28.2.41

Chang, S. T., and Cheng, S. S. (2002). "Antitermitic activity of leaf essential oils and components from Cinnamomum osmophelum," J. Agric. Food Chem. 50, 1389-1392. DOI: $10.1021 / \mathrm{jf010944n}$

Chang, S. T., Cheng, S. S., and Wang, S. Y. (2001). "Antitermitic activity of essential oils and components from Taiwania (Taiwania cryptomerioides)," J. Chem. Ecol. 27, 717-724. DOI: $10.1023 / \mathrm{A}: 1010397801826$

Chang S. T., Wang S. Y., and Kuo, Y. H. (2003). "Resource and bioactive substances from Taiwania (Taiwania cryptomeriodes)," J. Wood Sci. 49, 1-4. DOI: $10.1007 / \mathrm{s} 100860300000$

Chang, S. T., Wang, S. Y., Wu, C. L., Chen, P. F., and Kuo, Y. H. (2000). "Comparisons of the antifungal activities of cadinane skeletal sesquiterpenoids from Taiwania (Taiwania cryptomerioides Hayata) heartwood," Holzforschung 54, 241-245. DOI: 10.1515/HF.2000.041

Chang, S. T., Wang, S. Y., Wu, C. L., Su, Y. C., and Kuo, Y. H. (1999). "Antifungal compounds in the ethyl acetate soluble fraction of the extractives of Taiwania (Taiwania cryptomerioides Hayata) heartwood," Holzforschung 53, 487-490. DOI: 10.1515/HF.1999.080

Cheng, S. S., Chung, M. J., Lin, C. Y., Wang, Y. N., and Chang, S. T. (2012). "Phytochemicals from Cunninghamia konishii Hayata act as antifungal agents," $J$. Agric. Food Chem. 60, 124-128. DOI: 10.1021/jf2042196

Cheng, S. S., Lin, H. Y., and Chang, S. T. (2005). "Chemical composition and antifungal activity of essential oils from different tissues of Japanese cedar (Cryptomeria japonica)," J. Agric. Food Chem. 53, 614-619. DOI: 10.1021/jf0484529

Cheng, S. S., Liu, J. Y., Chang, E. H., and Chang, S. T. (2008). "Antifungal activity of cinnamaldehyde and eugenol congeners against wood-rot fungi," Bioresource Technol. 99, 5145-5149. DOI: 10.1016/j.biortech.2007.09.013

Cheng, S. S., Lin, C. Y., Gu, H. J., and Chang, S.T. (2011). "Chemical composition and antifungal activities of wood and leaf essential oils from Cunninghamia konishii Hayata," J. Wood Chem. Technol. 31, 204-217. DOI: 10.1080/02773813.2010.515049

Cheng, S. S., Liu, J. Y., Hsui, Y. R., and Chang, S. T. (2006). "Chemical polymorphism and antifungal activity of essential oils from leaves of different provenances of indigenous cinnamon (Cinnamomum osmophloeum)," Bioresource Technol. 97, 306312. DOI: 10.1016/j.biortech.2005.02.030

Cheng, S. S., Wu, C. L., Chang, H. T., Kao, Y. T., and Chang, S. T. (2004). "Antitermitic and antifungal activities of essential oil of Calocedrus fromosana leaf and its compounds," J. Chem. Ecol. 30, 1957-1967. DOI:

10.1023/B:JOEC.0000045588.67710.74 
EU Directive 98/8/EC (2012). "Directive 98/8/EC concerning the placing biocidal products on the market, Assessment Report, Didecyldimethylammonium chloride Product-type PT * (Wood preservative), European Union, Brussels, Belgium.

Eller, F. J. (2018). "Eastern red cedar: Cedarwood oil extraction and bioactivity," International News on Fats, Oils, and Related Materials (INFORM) May 2018, 29, 18-21. DOI: 10.21748/inform.05.2018.18

Eller, F. J., Clausen, C. A., Green, F., and Taylor, S. L. (2010). "Critical fluid extraction of Juniperus virginiana L. and bioactivity of extracts against subterranean termites and wood-rot fungi," Ind. Crops Prod. 32, 481-485. DOI:

10.1016/j.indcrop.2010.06.018

Eller, F. J., Hay, W. T., Kirker, G. T., Mankowski, M. E., and Selling, G. W. (2018). "Hexadecyl ammonium chloride amylose inclusion complex to emulsify cedarwood oil and treat wood against termites and wood-decay fungi," Inter. Biodeterior. Biodegrad. 129, 95-101. DOI: 10.1016/j.ibiod.2018.01.010

Eller, F. J., and King, J. W. (2000). "Supercritical carbon dioxide extraction of cedarwood oil: A study of extraction parameters and oil characteristics," Phytochem. Anal. 11, 226-231. DOI: 10.1002/1099-1565(200007/08)11:4<226::AIDPCA524>3.0.CO;2-7

Eller, F. J., Kirker, G. T., Mankowski, M. E., Hay, W. T., and Palmquist, D. E. (2020). "Effect of burgundy solid extracted from Eastern red cedar heartwood on subterranean termites and wood-decay fungi," Ind. Crops Prod. 144, 112023. DOI: 10.1016/j.indcrop.2019.112023

Fanta, G. F., Felker, F. C., Selling. G. W., Hay, W. T., and Biswas, A. (2016). "Poly(vinyl alcohol) composite films with high percent elongation prepared from amylose-fatty ammonium salt inclusion complexes," J. Appl. Polym. Sci. 133, 44110. DOI: 10.1002/app.44110

French, J. R. J., Robinson, P. J., Yazaki, Y., and Hillis, W. E. (1979). "Bioassays of extracts from white cypress pine (Callitris columellaris F Muell) against subterranean termites," Holzforschung 33, 144-148. DOI: 10.1515/hfsg.1979.33.5.144

Gupta, A., Sharma, S., and Naik, S. N. (2011). "Biopesticidal value of selected essential oils against pathogenic fungus, termites, and nematodes," Inter. Biodeter. Biodeg. 65, 703-707. DOI: 10.1016/j.ibiod.2010.11.018

Hassan, B., Mankowski, M. E., Kirker, G. T., and Ahmed, S. (2017). "Effects of heartwood extractives on symbiotic protozoan communities and mortality in two termite species," Inter. Biodeter. Biodeg. 123, 27-36. DOI: 10.1016/j.ibiod.2017.05.023

Hay, W. T., Fanta, G. F., Felker, F. C., Peterson, S. C., Skory, C. D., Hojilla-Evangelista, M. P., Biresaw, G., and Selling, G. W. (2019). "Emulsification properties of amylosefatty sodium salt inclusion complexes," Food Hydrocolloids 90, 490-499. DOI: 10.1016/j.foodhyd.2018.12.038

Kard, B., Hiziroglu, S., and Payton, M. E. (2007). "Resistance of redcedar panels to damage by subterranean termites (Isoptera: Rhinotermitidae)," For. Prod. J. 57, 7479.

Kard, B. M., and Mallette, E. J. (1997). "Resistance of six wood products used in paneling to Reticulitermes flavipes (Isoptera: Rhinotermitidae)" J. Econ. Entomol. 90, 178-182. DOI: $10.1093 /$ jee/90.1.178 
Kazemi, S. M., Hosseinzadeh, A., and Rezaei, M. B. (2006). "The effect of woody and non woody plants extractives on microbial resistance of non-durable species," $J$. Agric. Sci. Nat. Resour. 13, 183-193.

Kirker, G. T., Bishell, A. B., and Lebow, P. K. (2016). "Laboratory evaluations of durability of southern pine pressure treated with extractives from durable wood species," J. Econ. Entomol. 109, 259-266. DOI: 10.1093/jee/tov286

Kirker, G. T., Blodgett, A. B., Arango, R. A., Lebow, P. K., and Clausen, C. A. (2013). "The role of extractives in naturally durable wood species," Inter. Biodeterior. Biodegrad. 82, 53-58. DOI: 10.1016/j.ibiod.2013.03.007

Konemann, C. E., Kard, B. M., and Payton, M. E. (2014). "Palatability of field-collected eastern redcedar, Juniperus virginiana L., components to subterranean termites (Isoptera: Rhinotermitidae)," J. Kansas Entomol. Soc. 87, 2014, 269-279. DOI: 10.2317/JKES130619.1

Kose, C., and Taylor, A. M. (2012). "Evaluation of mold and termite resistance of included sapwood in eastern redcedar," Wood Fiber Sci. 44, 319-324.

Li, Q., Lin, J. G., and Liu, J. (2013). "Decay resistance of wood treated with extracts of Cinnamomum camphora xylem," BioResources 8(3), 4208-4217. DOI: 10.15376/biores.8.3.4208-4217

Lipeh, S., Schimleck, L. R., Mankowski, M. E., McDonald, A. G. and Morrell, J. J. (2020). "Relationship between attenuated total reflectance Fourier transform infrared spectroscopy of western juniper and natural resistance to fungal and termite attack," Holzforschung 74, 246-259. DOI: 10.1515/hf-2019-0096

Mankowski, M. E., Boyd, B., Hassan, B., and Kirker, G. T. (2016). "GC-MS characterizations of termiticidal heartwood extractives from wood species utilized in Pakistan," in: Proceedings IRG Annual Meeting, (ISSN 2000-8953) IRG/WP 1610857, The International Research Group on Wood Protection, Lisbon, Portugal.

Mansour, M. M., and Salem, M. Z. M. (2015). "Evaluation of wood treated with some natural extracts and Paraloid B-72 against the fungus Trichoderma harzianum: wood elemental composition, in-vitro and application evidence," Inter. Biodeterior. Biodegr. 100, 62-69. DOI: 10.1016/j.ibiod.2015.02.009

McDaniel, C. A., and Dunn, B. S. (1994). "Can wood extractives be used as wood protectants?,” Proc. Symp. Curr. Res. Chem. Sci. Gen. Tech. Rep. Soc. 101, 61-63.

McDaniel, C. A., Klocke, J. A., and Balandrin, M .F. (1989). "Major antitermitic wood extractive components from eastern red cedar, Juniperus virginiana," Mater. Org. 24, 301-331.

Morita, S. I., Hidaka, T., and Yatagai, M. (1997). “Antifungal compounds of the extractives of Yakusugi (Cryptomeria japonica D. Don)," Wood Preserv. 23, 11-19. DOI: $10.5990 /$ jwpa.23.61

Mun, S. P., and Prewitt, L. (2011). "Antifungal activity of organic extracts from Juniperus virginiana heartwood against wood decay fungi," For. Prod. J. 61, 443449. DOI: 10.13073/0015-7473-61.6.443

Pandey, A., Chattopadhyay, P., Banerjee, S., Pakshirajan, K., and Singh, L. (2012). "Antitermitic activity of plant essential oils and their major constituents against termite Odontotermes assamensis Holmgren (Isoptera: Termitidae) of North East India," Inter. Biodeter. Biodeg. 75, 63-67. DOI: 10.1016/j.ibiod.2012.09.004

Saha Tchinda, J.-B., Ndikontar, M. K., Belinga, A. D. F., Mounguengui, S., Njankouo, J. M., Durmacay, S., and Gerardin, P. (2018). "Inhibition of fungi with wood extractives 
and natural durability of five Cameroonian wood species," Ind. Crops Prod. 123:183191. DOI: 10.1016/j.indcrop.2018.06.078

Salem, M. Z. M., Zidan, Y. E., Mansour, M. M. A., El-Hadidi, N. M. N., and Abo-Elgat, W. A. A. (2016). "Antifungal activities of two essential oils used in the treatment of three commercial woods deteriorated by five common mold fungi," Inter. Biodeter. Biodeg. 106, 88-96. DOI: 10.1016/j.ibiod.2015.10.010

Schultz, T. P., and Nicholas, D. D. (2002). "Development of environmentally-benign wood preservatives based on the combination of organic biocides with antioxidants and metal chelators," Phytochemistry 61, 555-560. DOI: 10.1016/S00319422(02)00267-4

Singh, T., and Singh, A. P. (2012). "A review on natural products as wood protectant," Wood Sci. Technol. 46, 851-70. DOI: 10.1007/s00226-011-0448-5

Smith, A. L., Campbell, C. L., Walker, D. B., and Hanover, J. W. (1989). "Extracts from black locust as wood preservatives: Extraction of decay resistance from black locust heartwood," Holzforshung 43, 293-296. DOI: 10.1515/hfsg.1989.43.5.293

Smith, K. T., and Glaeser, J. A. (2013). "Skeleton decay in eastern Red Cedar," Arborist News 22:32-34.

Tascioglu, C., Yalcin, M., Sen, S., and Akcay, C. (2013). “Antifungal properties of some plant extracts used as wood preservatives," Inter. Biodeter. Biodeg. 85, 23-28. DOI: 10.1016/j.ibiod.2013.06.004

Taylor, A. M., Gartner, B. L, and Morrell, J. J. (2002). "Heartwood formation and natural durability - A review," Wood Fiber Sci. 34, 587-611.

Taylor, A. M., Gartner, B. L., Morrell, J. J., and Tsunoda, K. (2006). "Effects of heartwood extractive fractions of Thuja plicata and Chamaecyparis nootkatensis on wood degradation by termites or fungi," J. Wood Sci. 52, 147-153. DOI: 10.1007/s10086-005-0743-6

Tumen, I., Eller, F. J., Clausen, C. A., and Teel, J. A. (2013). “Antifungal activity of heartwood extracts from three Juniperus species," BioResources 8(1), 12-20. DOI: 10.15376/biores.8.1.12-20

Valette, N., Perrot, T., Sormani, R., Gelhaye, E, and Morel-Rouhier, M. (2017). "Antifungal activities of wood extractives," Fungal Bio. Rev. 31, 113-23. DOI: 10.1016/j.fbr.2017.01.002

Wan, H., Wang, X. M., and Yang, D. Q. (2007). "Utilizing eastern white cedar to improve the resistance of strand boards to mould and decay fungi," For. Prod. J. 57, 54-59.

Wang, S. Y., Chen, P. F., and Chang, S. T. (2005a). "Antifungal activities of essential oils and their constituents from indigenous cinnamon (Cinnamomum osmophloeum) leaves against wood decay fungi," Bioresource Technol. 96, 813-818. DOI: 10.1016/j.biortech.2004.07.010

Wang, S. Y., Wu, C. L., Chu, F .H., Chien, S. C., Kuo, Y. H., Shyur, L. F., and Chang, S. T. (2005b). "Chemical composition and antifungal activity of essential oil from Chamaecyparis formosensis wood," Holzforschung 59, 295-299. DOI: 10.1515/HF.2005.049

Wang, J., Li, J., Li, S., Freitang, C., and Morrell, J. J. (2011). "Antifungal activities of Cunninghamia lanceolate heartwood extractives," BioResources 6(1), 606-614. DOI: 10.15376/biores.6.1.606-614 
Watanabe, Y., Mihara, R., Mitsunaga, T., and Yoshimura, T. (2005). "Termite repellent sesquiterpenoids from Callitris glaucophylla heartwood," J. Wood Sci. 51, 514-519. DOI: $10.1007 / \mathrm{s} 10086-004-0683-6$

Wu, C. L., Chien, S. C., Wang, S. Y., Ku, Y. H., and Chang, S. T. (2005). "Structureactivity relationships of cadinane-type sesquiterpene derivatives against wood-decay fungi," Holzforschung 59, 620-627. DOI: 10.1515/HF.2005.100

Wu, C. C., Wu, C. L., Huang, S. L., and Chang, H. T. (2012). "Antifungal activity of liriodenine from Michelia formosana heartwood against wood-rotting fungi," Wood Sci. Technol. 46, 737-747. DOI: 10.1007/s00226-011-0428-9

Xie, Y. J., Yang, Z. L., Cao, D. Y., Rong, F., Ding, H., and Zhang, D. Y. (2015). "Antitermitic and antifungal activities of eugenol and its congeners from the flower buds of Syzgium aromaticum (Clove)," Ind. Crops Prod. 77, 780-786. DOI: 10.1016/j.indcrop.2015.09.044

Xie, Y., Wang, Z., Huang, Q., and Zhang, D. (2017). “Antifungal activity of several essential oils and major components against wood-rot fungi," Ind. Crops Prod. 2017. 108, 278-85. DOI: 10.1016/j.indcrop.2017.06.041

Yang, D. Q. (2009). "Potential utilization of plant and fungal extracts for wood protection," For. Prod. J. 59, 97-103.

Yen, T. B., Chang, H. T., Hsieh, C. C., and Chang, S. T. (2008). "Antifungal properties of ethanolic extract and its active compounds from Calocedrus macrolepis var. formosana (Florin) heartwood," Bioresource Technol. 99, 4871-4877. DOI: 10.1016/j.biortech.2007.09.037

Zhu, B. C., Henderson, G., Chen, F., Fei, H., and Laine, R. A. (2001). "Evaluation of vetiver oil and seven insect-active essential oils against the Formosan subterranean termite," J. Chem. Ecol. 27, 1617-1625. DOI: 10.1023/A:1010410325174

Article submitted: September 21, 2020; Peer review completed: November 8, 2020; Revised version received and accepted: December 7, 2020; Published: December 11, 2020.

DOI: $10.15376 /$ biores.16.1.893-910 